\title{
Secondhand Smoke Exposure of Expectant Mothers in China: Factoring in the Role of Culture in Data Collection
}

Zhaohui $\mathrm{Su}^{1}, \mathrm{PhD}$; Dean McDonnell ${ }^{2}, \mathrm{PhD}$; Jaffar Abbas ${ }^{3}, \mathrm{PhD}$; Lili Shi ${ }^{3}$, PhD; Yuyang Cai ${ }^{3,4}, \mathrm{PhD}$; Ling Yang ${ }^{3}$, $\mathrm{PhD}$

${ }^{1}$ Center on Smart and Connected Health Technologies, Mays Cancer Center, School of Nursing, University of Texas Health San Antonio, San Antonio, TX, United States

${ }^{2}$ Department of Humanities, Institute of Technology Carlow, Carlow, Ireland

${ }^{3}$ School of Public Health, Shanghai Jiao Tong University School of Medicine, Shanghai, China

${ }^{4}$ China Institute for Urban Governance, Shanghai Jiao Tong University, Shanghai, China

\section{Corresponding Author:}

Zhaohui Su, PhD

Center on Smart and Connected Health Technologies, Mays Cancer Center

School of Nursing

University of Texas Health San Antonio

7703 Floyd Curl Drive

San Antonio, TX, 78229

United States

Phone: 15128399965

Email: $\underline{\text { szh@utexas.edu }}$

\section{Abstract}

Cancer is the leading cause of death worldwide. Tobacco smoking, including secondhand smoking, causes cancer and is responsible for over $22 \%$ of global cancer deaths. The adverse impacts of secondhand smoke are more pronounced for expectant mothers, and can deteriorate both mothers' and infants' health and well-being. Research suggests that secondhand smoke significantly increases expectant mothers' risk of miscarriage, cancer, and other chronic disease conditions, and exposes their unborn babies to an increased likelihood of having life-long poor health. In China, a pregnant woman's family members, such as her husband, parents, or in-laws, are the most likely people to be smoking around her. Due to traditional Chinese cultural practices, even though some expectant mothers understand the harm of secondhand smoke, they may be reluctant to report their family members' smoking behaviors. Resulting in severe underreporting, this compromises health experts' ability to understand the severity of the issue. This paper proposes a novel approach to measure secondhand smoke exposure of pregnant women in the Chinese context. The proposed system could act as a stepping stone that inspires creative methods to help researchers more accurately measure secondhand smoking rates of expectant mothers in China. This, in turn, could help health experts better establish cancer control measures for expectant mothers and decrease their cancer risk.

(JMIR Cancer 2021;7(4):e24984) doi: 10.2196/24984

\section{KEYWORDS}

cancer; secondhand smoking; secondhand smoke; expectant mothers; pregnant women; China; transitional Chinese culture; "doing the month"; smoking; pregnancy; women; China; culture; behavior

\section{Background}

Cancer is the leading cause of death worldwide [1]. Tobacco smoking, including secondhand smoking, causes cancer and is responsible for over 22\% of global cancer deaths [2]. In 2017 alone, 62.9 million disability-adjusted life years were lost in China due to cancer [3]. With the current prevalence of smoking, the situation is expected to worsen in the future [4]. China has the largest population of tobacco smokers worldwide-one in every three smokers across the globe is Chinese [4]. Different from other human addictions (eg, opioids), tobacco smoking not only harms smokers' health but also harms the health of individuals exposed to secondhand smoke [5].

While smoking has been declining in China (eg, among Chinese adults aged 30-69 years, $11.0 \%$ of smokers quit in 2010 compared to $4.2 \%$ quit rates in 1996), secondhand smoking remains a persistent public health issue that harms people's health and well-being [6]. Secondhand smoking can be 
understood as nonsmokers' exposure to smoke from tobacco products due to regular contact with smokers in close proximity to them [7]. Individuals subjected to secondhand smoke face unique health challenges despite not smoking cigarettes. They are exposed to the same set of detrimental health consequences associated with tobacco smoking, ranging from physical health consequences (eg, an elevated risk of cancer) to pronounced psychological health challenges [8].

\section{Danger of Secondhand Smoke for Expectant Mothers}

Recent evidence shows that Chinese women exposed to secondhand smoke often experience a significant decline in cognitive functions, such as memory, that can last up to two years [9]. However, the situation might be worse for expectant mothers. Women may experience various health issues during pregnancy including venous thromboembolism, diabetes, hypertension, and heart disease; in addition, women are at increased risk of domestic violence when pregnant [10-12]. Additionally, for this community, exposure to toxic materials often results in harm to both the women themselves and their unborn babies [13-15]. In other words, exposure to harmful substances, such as toxic secondhand smoke, harms pregnant women at a time when health risks are more likely to affect their long-term health outcomes, in addition to causing substantial harm to their unborn babies' health [16-18]. Furthermore, secondhand smoke and its adverse effects are associated with an increased risk of infant mortality, including sudden infant death syndrome [19] (Figure 1).

Figure 1. A schematic representation of the increased health risks of secondhand smoking for expectant mothers and their infants.

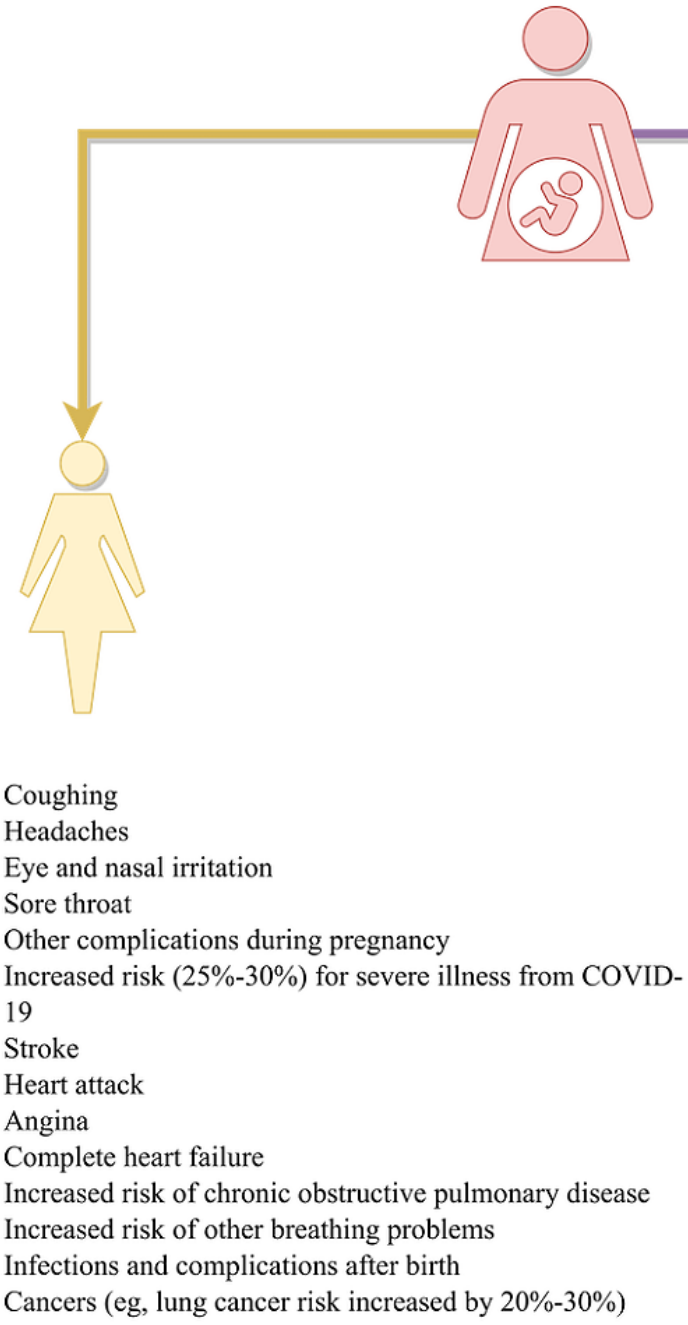

\section{"Doing the Month": A Unique Risk Factor for Secondhand Smoke Exposure}

Secondhand smoking might have an even more significant impact on expectant Chinese women due to cultural practices. In China, it is common practice for partners, parents, or in-laws to take care of the pregnant woman during and beyond

pregnancy to meet her basic needs [20]. Owing partially to traditional Chinese culture and social norms, immediately after women give birth to their babies, these helpers are also expected to attend to the needs and wants of women and their newborn infants during the "doing the month" ritual [21]. When followed stringently, "doing the month," a traditional Chinese cultural practice that dates back more than 2000 years, requires women to follow an extensive list of rules. These rules include not 
leaving the house, refraining from contacting water or wind (eg, not washing one's hair, taking full-body showers, or opening the window), and not consuming foods that have a "cold" nature, among other things, for a full month [22]. In a recent study of 2615 Chinese women, researchers found that $60.5 \%$ of women surveyed did not go outside during the first month after childbirth, while $30.4 \%$ of the women only went outside once or twice [23].

Due to the physical constraints of the "doing the month" practice, understandably, women who follow the custom closely often have to rely on help from family members or formal caregivers [24]. Though "doing the month" can cause significant discomfort, with some customs not supported by scientific evidence, a considerable number of young Chinese mothers still practice the ritual, following the customs of their ancestors [25]. It is common to receive support from husbands and senior members of a family during pregnancy and throughout the "doing the month" ritual [24], which can result in many family members living in the same household for some time. Although this arrangement can offer women substantial help, the extended time spent in close proximity may introduce a series of risk factors into a household [26]. Despite public smoking rates declining due to recent antismoking public policies, one unintended consequence is that smokers are more likely to smoke indoors [27], which affects people who may not be able to leave such an environment.

Deeply rooted in traditional Chinese culture is the consensus that young adults are expected to avoid correcting the behavior of seniors, even if the behavior is known to be health-damaging [28]. This cultural norm might be more pronounced when it comes to behaviors related to in-laws, so as to not appear confrontational and disrespectful. Regardless, these health-damaging behaviors, such as secondhand smoking, may harm women and their infants [28]. Furthermore, though women's rights are steadily improving in China, it is essential to acknowledge that women's overall welfare and well-being is still primarily overshadowed by that of men [29].

However, positive changes are occurring. A growing body of literature suggests that there has been a change in Chinese people's attitudes and behaviors toward complying with traditional Chinese cultural values and social norms in recent years. Research finds that though the influence of traditional Chinese culture on Chinese social norms and practices (such as collectivism) is still ongoing and tangible, its hold over young adults is waning [30]. Furthermore, as the number of working women increases, more women gain financial freedom, bringing equal rights and gender equality to the forefront [31]. Overall, accumulating evidence indicates that values that are cherished by older Chinese generations might no longer be valued to the same degree by their younger counterparts [32].

\section{Measuring Smoking Around Expectant Mothers}

This cultural shift may have an impact on how pregnant women address issues such as being exposed to harm through secondhand smoke from their husbands and older family members [33]. Due to recent cultural shifts, pregnant Chinese women are more likely to be aware of the devastating effects secondhand smoke can have on themselves and their unborn babies. These shifts may eventually result in mothers persuading their husbands or senior family members to change their smoking behaviors; mothers may even find a way to avoid these toxic environments filled with secondhand smoke. However, while this social phenomenon may be occurring, it is difficult to capture in a nonintrusive research setting [34]. Owing partially to ingrained cultural values and social norms, pregnant Chinese women may be reluctant to share their norm-defying behaviors toward their senior family members with researchers.

What might be possible, however, is to gauge this phenomenon from a different yet closely related angle. To this end, we propose a new method to gauge pregnant women's rates of secondhand smoking. Different from traditional methods, which ask people how often they are exposed to secondhand smoke directly, we believe that a pregnant woman's exposure to secondhand smoke may be more accurately gauged by asking about the smoking frequency of the woman's family members (ie, husbands and other relatives) when they are in close proximity to the woman, especially during the "doing the month" period. In other words, there might be discrepancies in secondhand smoking rates reported by pregnant women due to deep-rooted cultural influences (eg, not wanting to accuse their family members, who play a pivotal role in the "doing the month" ritual, of reckless health behaviors that might harm the health and well-being of the expectant mothers, unborn children, and smokers themselves).

One way to gauge potential discrepancies in secondhand smoking rates reported by expectant mothers is by comparing these rates with smoking rates reported by the family members of these women. That is to say, rather than asking pregnant women about their exposure to secondhand smoke, more accurate information may be gleaned by directly asking family members about smoking frequency and duration in the presence of the pregnant woman. To further ensure that secondhand smoking faced by expectant mothers can be captured accurately, we believe it is important to collect data from expectant mothers and their family members separately (eg, survey conducted individually, rather than as a family unit), so that the role of social pressure in influencing survey results will be limited.

Protecting pregnant women from the harm of secondhand smoking safeguards the health and well-being of unborn children. Research that focuses on understanding women's exposure to secondhand smoke and the various factors that contribute to their experience of secondhand smoking is urgently needed. The proposed approach is tangible and realistic from a research perspective. Understanding the relationship between traditional Chinese cultural values and social norms, women's awareness of secondhand smoking and their background information (eg, education levels), and the women's actual exposure to secondhand smoke from their husbands and other family members can help researchers obtain valuable insights needed to develop intervention measures to protect this vulnerable population [35]. 


\section{Concluding Remarks}

In 2018, it is estimated that 4,285,033 new cancer cases were diagnosed in China, among which 1,919,023 were female [3]. Mounting evidence suggests that tobacco smoking increases the risk of many types of cancers [1]. Different from environmental factors such as air pollution, which might be more difficult to control and contain [36], tobacco smoking can be curbed in a timely and cost-effective manner [37], as seen in successful tobacco control interventions established in countries such as the United States. This insight is particularly promising for expectant mothers, as the adverse impacts of secondhand smoke are more pronounced for this population, and can harm both the mother's and the infant's health and well-being [13-18]. However, to develop a tailored and targeted tobacco control plan, health experts and government officials need to understand how much secondhand smoke expectant mothers are exposed to. We hope that the current proposed methods and future improved measures will lead to a better understanding of how much secondhand smoke expectant mothers are exposed to, as that knowledge is essential for designing and deploying effective interventions to protect expectant mothers and their infants from the harms of smoking and risk of cancer

\section{Acknowledgments}

The authors wish to express their gratitude for the constructive input offered by the editor and reviewers.

\section{Authors' Contributions}

ZS conceived the work, reviewed the literature, and drafted and edited the manuscript. DMD, JA, LS, YC, and LY reviewed the literature and edited the manuscript. All authors approved the manuscript for submission.

\section{Conflicts of Interest}

None declared.

\section{References}

1. Global health observatory. World Health Organization. URL: https://www.who.int/data/gho [accessed 2020-03-01]

2. Cancer. World Health Organization. URL: https://www.who.int/news-room/fact-sheets/detail/cancer [accessed 2020-03-02]

3. Sun D, Cao M, Li H, He S, Chen W. Cancer burden and trends in China: A review and comparison with Japan and South Korea. Chin J Cancer Res 2020 Apr;32(2):129-139 [FREE Full text] [doi: 10.21147/j.issn.1000-9604.2020.02.01] [Medline: 32410791]

4. Parascandola M, Xiao L. Tobacco and the lung cancer epidemic in China. Transl Lung Cancer Res 2019 May;8(Suppl 1):S21-S30 [FREE Full text] [doi: 10.21037/tlcr.2019.03.12] [Medline: 31211103]

5. Carreras G, Lugo A, Gallus S, Cortini B, Fernández E, López MJ, TackSHS Project Investigators. Burden of disease attributable to second-hand smoke exposure: A systematic review. Prev Med 2019 Dec;129:105833 [FREE Full text] [doi: 10.1016/j.ypmed.2019.105833] [Medline: 31505203]

6. Liu S, Zhang M, Yang L, Li Y, Wang L, Huang Z, et al. Prevalence and patterns of tobacco smoking among Chinese adult men and women: findings of the 2010 national smoking survey. J Epidemiol Community Health 2017 Feb 22;71(2):154-161 [FREE Full text] [doi: 10.1136/jech-2016-207805] [Medline: 27660401]

7. National Center for Chronic Disease Prevention and Health Promotion (US) Office on Smoking and Health. The Health Consequences of Smoking-50 Years of Progress: A Report of the Surgeon General. In: Reports of the Surgeon General. Atlanta (GA): Centers for Disease Control and Prevention (US); 2014.

8. Xia C, Zheng R, Zeng H, Zhou M, Wang L, Zhang S, et al. Provincial-level cancer burden attributable to active and second-hand smoking in China. Tob Control 2019 Nov 15;28(6):669-675. [doi: 10.1136/tobaccocontrol-2018-054583] [Medline: $\underline{\text { 30322976] }}$

9. Pan X, Luo Y, Roberts AR. Secondhand Smoke and Women's Cognitive Function in China. Am J Epidemiol 2018 May 01;187(5):911-918. [doi: 10.1093/aje/kwx377] [Medline: 29370335]

10. Varshavsky J, Smith A, Wang A, Hom E, Izano M, Huang H, et al. Heightened susceptibility: A review of how pregnancy and chemical exposures influence maternal health. Reprod Toxicol 2020 Mar;92:14-56 [FREE Full text] [doi:

10.1016/j.reprotox.2019.04.004] [Medline: 31055053]

11. Hall PS, Nah G, Vittinghoff E, Parker DR, Manson JE, Howard BV, et al. Relation of Pregnancy Loss to Risk of Cardiovascular Disease in Parous Postmenopausal Women (From the Women's Health Initiative). Am J Cardiol 2019 May 15;123(10):1620-1625 [FREE Full text] [doi: 10.1016/j.amjcard.2019.02.012] [Medline: 30871746 ]

12. Wang T, Liu Y, Li Z, Liu K, Xu Y, Shi W, et al. Prevalence of intimate partner violence (IPV) during pregnancy in China: A systematic review and meta-analysis. PLoS One 2017 Oct 2;12(10):e0175108 [FREE Full text] [doi:

10.1371/journal.pone.0175108] [Medline: 28968397]

13. Tang J, Shen J, Zhang S, Ho H, Ran S. A Pilot Study on Secondhand Smoke Exposure Among Pregnant Women in Chongqing, China: A Combined Questionnaire, Saliva Cotinine Test, and Ultrasound Flow Index Analysis. Front Public Health 2020 Jul 29;8:290 [FREE Full text] [doi: 10.3389/fpubh.2020.00290] [Medline: 32903734] 
14. Wang M, Wang Z, Zhang M, Zhao Z. Maternal passive smoking during pregnancy and neural tube defects in offspring: a meta-analysis. Arch Gynecol Obstet 2014 Mar 13;289(3):513-521. [doi: 10.1007/s00404-013-2997-3] [Medline: 23942772]

15. Ferraro AA, Rohde LA, Polanczyk GV, Argeu A, Miguel EC, Grisi SJFE, et al. The specific and combined role of domestic violence and mental health disorders during pregnancy on new-born health. BMC Pregnancy Childbirth 2017 Aug 01;17(1):257 [FREE Full text] [doi: 10.1186/s12884-017-1438-x] [Medline: 28764678]

16. Liu J, Leung PWL, McCauley L, Ai Y, Pinto-Martin J. Mother's environmental tobacco smoke exposure during pregnancy and externalizing behavior problems in children. Neurotoxicology 2013 Jan;34:167-174 [FREE Full text] [doi: 10.1016/j.neuro.2012.11.005] [Medline: 23178460]

17. Lin Q, Hou X, Yin X, Wen G, Sun D, Xian D, et al. Prenatal Exposure to Environmental Tobacco Smoke and Hyperactivity Behavior in Chinese Young Children. Int J Environ Res Public Health 2017 Sep 27;14(10):1-12 [FREE Full text] [doi: 10.3390/ijerph14101132] [Medline: 28953223]

18. Yang S, Xu L, He Y, Jiang C, Jin Y, Cheng KK, et al. Childhood secondhand smoke exposure and pregnancy loss in never smokers: the Guangzhou Biobank Cohort Study. Tob Control 2017 Nov 23;26(6):697-702 [FREE Full text] [doi: 10.1136/tobaccocontrol-2016-053239] [Medline: 28011924]

19. Qu Y, Chen S, Pan H, Zhu H, Yan C, Zhang S, et al. Exposure to tobacco smoke and stillbirth: a national prospective cohort study in rural China. J Epidemiol Community Health 2020 Apr 09;74(4):315-320. [doi: 10.1136/jech-2019-213290] [Medline: 31919145$]$

20. Lau Y, Yin L, Wang Y. Antenatal depressive symptomatology, family conflict and social support among Chengdu Chinese women. Matern Child Health J 2011 Nov 19;15(8):1416-1426. [doi: 10.1007/s10995-010-0699-z] [Medline: 20957512]

21. Ding G, Tian Y, Yu J, Vinturache A. Cultural postpartum practices of 'doing the month' in China. Perspect Public Health 2018 May;138(3):147-149. [doi: 10.1177/1757913918763285] [Medline: 29635986]

22. Holroyd E, Lopez V, Chan SWC. Negotiating "Doing the month": an ethnographic study examining the postnatal practices of two generations of Chinese women. Nurs Health Sci 2011 Mar;13(1):47-52. [doi: 10.1111/j.1442-2018.2011.00575.x] [Medline: 21352433]

23. Ding G, Niu L, Vinturache A, Zhang J, Lu M, Gao Y, Shanghai Birth Cohort Study. "Doing the month" and postpartum depression among Chinese women: A Shanghai prospective cohort study. Women Birth 2020 Mar;33(2):e151-e158. [doi: 10.1016/j.wombi.2019.04.004] [Medline: 31060983]

24. Yeh YC, St John W, Chuang YH, Huang YP. The care needs of postpartum women taking their first time of doing the month: a qualitative study. Contemp Nurse 2017 Oct;53(5):576-588. [doi: 10.1080/10376178.2017.1389615] [Medline: 28992751]

25. Zheng X, Watts K, Morrell J. Chinese primiparous women's experience of the traditional postnatal practice of "Doing the month": A descriptive method study. Jpn J Nurs Sci 2019 Jul;16(3):253-262 [FREE Full text] [doi: 10.1111/jijns.12232] [Medline: 30259684$]$

26. Leung SKS, Arthur D, Martinson IM. Perceived stress and support of the Chinese postpartum ritual "doing the month". Health Care Women Int 2005 Mar;26(3):212-224. [doi: 10.1080/07399330590917771] [Medline: 15804694]

27. Yao T, Lee AH, Mao Z. Potential unintended consequences of smoke-free policies in public places on pregnant women in China. Am J Prev Med 2009 Aug;37(2 Suppl):S159-S164 [FREE Full text] [doi: 10.1016/j.amepre.2009.05.014] [Medline: 19591756]

28. Hwang KK. Filial Piety and Loyalty: Two Types of Social Identification in Confucianism. Asian Journal of Social Psychology 2020 Nov;2(1):163-183. [doi: 10.1111/1467-839X.00031]

29. Wang D, Xia Y. Couple relationships in China. In: Abela A, Vella S, Suzanne P, editors. Couple Relationships in a Global Context: Understanding love and intimacy across cultures. Cham: Springer International Publishing; 2020:107-124.

30. Weng L, Zhang YB, Kulich SJ, Zuo C. Cultural values in Chinese proverbs reported by Chinese college students. Asian J Soc Psychol 2020 Jun 04;24(2):232-243. [doi: 10.1111/ajsp.12415]

31. de Bruin A, Liu N. The urbanization-household gender inequality nexus: Evidence from time allocation in China. China Economic Review 2020 Apr;60:101301 [FREE Full text] [doi: 10.1016/j.chieco.2019.05.001]

32. Li X, Cao H, Curran MA, Fang X, Zhou N. Traditional Gender Ideology, Work Family Conflict, and Marital Quality among Chinese Dual-Earner Couples: A Moderated Mediation Model. Sex Roles 2020 Feb 11;83(9-10):622-635. [doi: 10.1007/s11199-020-01125-1]

33. Zhang L, Hsia J, Tu X, Xia Y, Zhang L, Bi Z, et al. Exposure to secondhand tobacco smoke and interventions among pregnant women in China: a systematic review. Prev Chronic Dis 2015 Mar 19;12:E35 [FREE Full text] [doi: 10.5888/pcd12.140377] [Medline: 25789496]

34. Shen Y, Messner SF, Liu J, Sampson RJ. What They Don't Know Says A Lot: Residents' Knowledge of Neighborhood Crime in Contemporary China. J Quant Criminol 2018 Dec 11;35(3):607-629. [doi: 10.1007/s10940-018-9401-1]

35. Astell-Burt T, Zhang M, Feng X, Wang L, Li Y, Page A, et al. Geographical Inequality in Tobacco Control in China: Multilevel Evidence From 98058 Participants. Nicotine Tob Res 2018 May 03;20(6):755-765. [doi: 10.1093/ntr/ntx100] [Medline: 28520988] 
36. Turner MC, Krewski D, Diver WR, Pope CA, Burnett RT, Jerrett M, et al. Ambient Air Pollution and Cancer Mortality in the Cancer Prevention Study II. Environ Health Perspect 2017 Aug 21;125(8):087013 [FREE Full text] [doi: 10.1289/EHP1249] [Medline: 28886601]

37. Holford TR, Meza R, Warner KE, Meernik C, Jeon J, Moolgavkar SH, et al. Tobacco control and the reduction in smoking-related premature deaths in the United States, 1964-2012. JAMA 2014 Jan 08;311(2):164-171. [doi: 10.1001/jama.2013.285112] [Medline: 24399555]

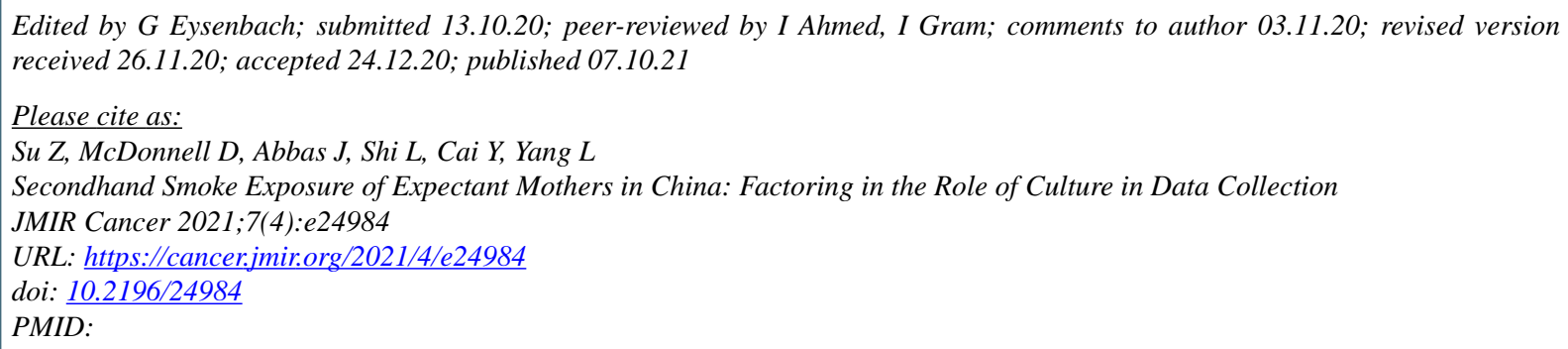

(CZhaohui Su, Dean McDonnell, Jaffar Abbas, Lili Shi, Yuyang Cai, Ling Yang. Originally published in JMIR Cancer (https://cancer.jmir.org), 07.10.2021. This is an open-access article distributed under the terms of the Creative Commons Attribution License (https://creativecommons.org/licenses/by/4.0/), which permits unrestricted use, distribution, and reproduction in any medium, provided the original work, first published in JMIR Cancer, is properly cited. The complete bibliographic information, a link to the original publication on https://cancer.jmir.org/, as well as this copyright and license information must be included. 